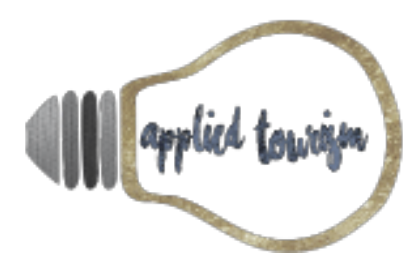

Volume 4, número 1, 2019, p. 18- 40

\title{
A EFICÁCIA DO USO DA REALIDADE VIRTUAL PARA O MARIKETING DO ATRATIVO TURÍSTICO USINA DE ITAIPU
}

\author{
Carolina Lima Della Monica \\ Mestranda em Tecnologias, Gestão e Sustentabilidade - UNIOESTE \\ C_carolinalima@hotmail.com \\ Eduardo Hack Neto \\ Doutor em Geografia pela UFPR e Universidade de Santiago de Compostela \\ Professor na Universidade Estadual do Oeste do Paraná - UNIOESTE \\ professoreduardohack@gmail.com
}

Recebido: 06 de setembro, 2018

Aprovado: 22 de outubro, 2018

\section{RESUMO}

A era digital provocou profundas mudanças nas relações de consumo. Neste contexto, as empresas devem acompanhar a revolução tecnológica para se manterem no mercado e conquistarem espaço na mente dos consumidores, criando momentos de envolvimento profundo com seus clientes e prospects. O estudo visa constatar a eficácia da utilização da realidade virtual como ferramenta de marketing do atrativo turístico Usina de Itaipu, por meio dos indicadores de reputação da empresa, risco percebido e engajamento do consumidor. A pesquisa foi descritiva, do tipo survey, onde os sujeitos entrevistados classificaram afirmações em escala Likert antes e depois da utilização dos óculos de realidade virtual, a fim de identificar a variação após o uso da tecnologia. As respostas foram organizadas em planilha, gerando tabelas que permitiram a comparação e análise dos dados, bem como o cálculo da média e desvio padrão de cada variável. Os resultados mostraram que as médias foram superiores após o uso da realidade virtual e houve maior consistência nas respostas, com a diminuição do desvio padrão, confirmando a eficácia do uso da realidade virtual como ferramenta de marketing de atrativos turísticos.

Palavras-chaves: Realidade virtual. Marketing. Tecnologia no Turismo. Usina de Itaipu. Eficácia. 


\section{INTRODUÇÃO}

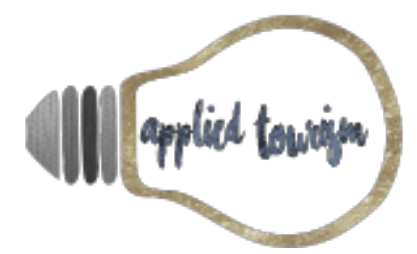

Volume 4, número 1, 2019, p. 18- 40

O avanço tecnológico possibilita novas formas de relacionamento e envolvimento das marcas com o cliente. Atualmente as pessoas vivem conectadas e tem acesso à internet na palma da mão, o que permite que as interações com a marca ocorram de forma online e offline a todo o momento e sem ordem prescrita (Kotler, Kartajaya \& Setiawan, 2017). De forma a acompanhar os avanços ciberculturais as práticas de marketing também evoluíram para o mundo digital (Okada \& Souza, 2011; Secretaria Especial de Comunicação Social do Brasil [Secom], 2016) e neste contexto, a capacidade de promover interações de envolvimento profundo com o cliente torna-se o diferencial para as marcas, que tem a tecnologia como aliada na ampliação das possibilidades de criação dessas interações (Kotler et al., 2017).

A realidade virtual $[\mathrm{RV}]$ é uma tecnologia apresentada pela primeira vez nos anos 60 . Sua funcionalidade é transportar pessoas para um mundo computadorizado tridimensional, com visualização em $360^{\circ}$ graus e possibilidades de interação nos cinco sentidos humanos, tornando a experiência muito próxima do mundo real (Kirner \& Tori, 2004; Siscoutto \& Kirner, 2007). Tais avanços tecnológicos estão possibilitando a popularização dessa tecnologia nos dias atuais, tendo como estimativa que até 2018 hajam 25 milhões de aparelhos de realidade virtual na mão de consumidores do mundo (Consultoria Gartner Group [GARTNER], 2015 como citado em Neef, 2015).

Para o marketing as possibilidades são infinitas e seu uso vem ganhando espaço em ações em todo o mundo (Gartner, 2016; 2017; Interactive Advertising Bureau [IAB], 2016). Um case atual no Brasil é o da Usina Hidrelétrica de Itaipu, que utiliza a realidade virtual em seus estandes institucionais na participação em eventos, apresentando a empresa para o usuário com uma visita virtual dentro da usina, percorrendo inclusive por locais restritos. O passeio virtual também é uma prévia do produto turístico comercializado pela empresa: o Circuito Especial; neste circuito é feita uma visita guiada real dentro da usina hidrelétrica e nas áreas de produção de energia. Dessa forma, a realidade virtual se torna uma ferramenta capaz de promover a interação de envolvimento profundo com a empresa e seus produtos, tendo um custo relativamente baixo, onde o principal investimento é em capital intelectual e criativo (IAB, 2016; Gartner, 2017).

Nesse sentido, ao verificar na literatura as possibilidades do uso da RV como ferramenta de marketing e o exemplo de aplicação do atrativo turístico Itaipu, esta pesquisa pretende mensurar o impacto do uso da realidade virtual na eficácia das ações de marketing de atrativos turísticos com base nos indicadores: de reputação da empresa, constatando a variação de percepção quanto ao comportamento da empresa, sua credibilidade, confiabilidade e responsabilidade; indicador de risco percebido, ao verificar a segurança do possível cliente em 


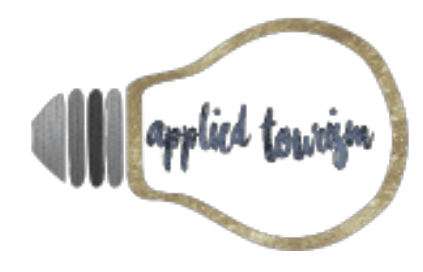

Volume 4, número 1, 2019, p. 18- 40

consumir o produto; e indicador de engajamento, mensurando a motivação do possível cliente em consumir e recomendar o produto após a experiência com a tecnologia de RV. Com os resultados pretende-se justificar os investimentos de marketing nessa tecnologia ao constatar o impacto que a RV causa nas percepções do consumidor.

\section{CIBERCULTURA E O MARKETING}

O avanço das Tecnologias da Informação e Comunicação [TIC] proporcionou a facilidade de acesso aos recursos tecnológicos, destarte provocou mudanças no modo como pessoas e empresas se relacionam, nas transações comerciais e de trabalho, entretenimento, entre outras (Kotler et al., 2017; Secom, 2016; Porciuncula \& Infante, 2016; Okada \& Souza, 2011). Schwarzelmüller (2005, p. 3) corrobora com essa afirmação quando considera que a cibercultura é uma "forma libertadora e democrática de expressão, de busca de informação e de conhecimento, que vem possibilitando novas formas de pensar, trabalhar, interagir, ensinar, aprender e viver".

As atividades de marketing e propaganda também foram fortemente afetadas pelas mudanças tecnológicas e evolução da web (Okada \& Souza, 2011; Secom, 2016), a ampliação do acesso à internet e do uso dos smartphones conduziu as empresas para o desenvolvimento do marketing digital, se fazendo presente nos locais que seus consumidores frequentam, ainda que sejam locais virtuais (Kotler et al., 2017; Okada \& Souza, 2011). Dessa forma, o marketing digital explora as mídias digitais para se comunicar com os consumidores que estão cada vez mais conectados, desta forma Kotler et al. (2017 p. 37 e 38) afirma que "em um mundo cada vez mais caracterizado pela alta tecnologia, a interação de envolvimento profundo está se tornando a nova diferenciação" e essa interação pode se tornar mais fascinante com o uso de interfaces de alta tecnologia, assim, a tecnologia é uma importante ferramenta para aprimorar o relacionamento da marca com o cliente por meio do marketing.

Consoante com Kotler et al. (2017), o processo de compra do consumidor da era da conectividade ocorre a partir de interações online offline, que devem "coexistir e serem complementares com o objetivo comum de oferecer uma experiência superior ao consumidor" (p. 44). Um estímulo online pode conduzir o consumidor à visitação da loja física (offline), a qual pode influenciar a utilização de um aplicativo (novamente online), ou seja, a todo o momento o consumidor pode vivenciar experiências virtuais e reais, não havendo um fluxo para que ocorra.

\section{REALIDADE VIRTUAL}

A realidade virtual é uma ferramenta que alinha a tecnologia como forma de proporcionar uma experiência única para os clientes. Desenvolvida a partir da linguagem VRML - Virtual Reality Modeling Language, a RV consiste na criação de ambientes computadorizados com modelagem tridimensional, onde um indivíduo pode imergir no Monica, C. L. D. \& NETO, E. H. (2019). A EFICÁCIA DO USO DA REALIDADE VIRTUAL PARA O MARKETING DO ATRATIVO TURÍSTICO USINA DE 


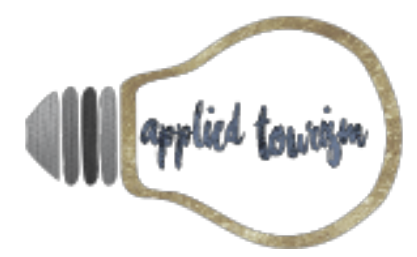

Volume 4, número 1, 2019, p. 18- 40

ambiente virtual, rompendo a barreira da tela dos aparelhos eletrônicos. A técnica permite a interação do usuário em tempo real em um ambiente simulado virtualmente, utilizando estímulos multissensoriais, como visão e audição, podendo também detectar suas ações como o caminhar, explorar e manipular objetos virtuais (Siscoutto \& Kirner, 2007; Kirner \& Tori, 2004; IAB, 2016). Se trata de transportar pessoas para ambientes simulados tão convincentes quanto o mundo real, que podem ser projetados a partir da realidade ou criações totalmente digitais em mundos imaginários.

Apesar da RV ter sido desenvolvida nos anos 60, entrou em evidência somente na década de 90 com o avanço tecnológico que possibilitou a execução da computação gráfica em tempo real. Contudo, ainda precisava de muitos equipamentos adicionais para que o usuário pudesse interagir dentro do ambiente virtual, como luvas especiais, capacete, óculos estereoscópicos, mouse 3D e por vezes até treinamento. Tais barreiras dificultaram a popularização da ferramenta, porém, a partir dos anos 2000, novos métodos vêm difundindo o seu uso (Siscoutto \& Kirner, 2007; Kirner \& Tori, 2004), tornando a RV uma nova forma de criar experiências únicas, inovadoras e emocionantes para prospects ${ }^{\mathrm{I}}$ da empresa, a fim de construir afinidade com a marca e um relacionamento customizado. Essa é uma tendência de mídia de marketing com custo relativamente baixo para anunciantes, onde empresas podem criar uma história ao redor da marca a ser explorada de acordo com a interação provocada pelo usuário, criando experiências mais engajadoras. A expectativa é que a realidade virtual seja uma ferramenta de vendas útil num futuro próximo (IAB, 2016; Gartner, 2016; 2017). Slobin (2015 como citado em Neef, 2015) afirma que "Dispositivos de vídeo usados na cabeça estão prestes a atingir o mainstream" ", com a previsão que o ápice do uso ocorra até 2027, "Eles [os óculos] ficarão mais baratos e serão dados com contratos de celular. Em breve, eles serão apenas mais uma engrenagem na sua vida. Onde os consumidores estiverem, as marcas irão". Há estimativa de que 25 milhões de equipamentos com recursos de RV estarão nas mãos dos consumidores globalmente até 2018 e até 2019 a tecnologia imersiva será utilizada por 20\% das empresas de grande porte. Um exemplo é o da Samsung Gear VR, óculos de RV para ser utilizado com o próprio celular Samsung modelos S6 e S7. Já existem também criações muito acessíveis dos óculos de RV, com modelos feitos com papelão ${ }^{\text {III }}$, podendo ser utilizado com qualquer celular, bastando ter o software instalado, o que torna a realidade virtual bastante acessível (Neef, 2015; IAB, 2016; Gartner, 2016; 2017).

\footnotetext{
${ }^{\text {I }}$ Potenciais clientes da empresa (Bogmann, 2000).

II Na tradução literal do inglês significa "convencional". No marketing, mainstream refere-se a cultura popular e é disseminado principalmente pelos meios de comunicação em massa.

III Google Cardboard https://vr.google.com/cardboard/

Monica, C. L. D. \& NETO, E. H. (2019). A EFICÁCIA DO USO DA REALIDADE VIRTUAL PARA O MARKETING DO ATRATIVO TURÍSTICO USINA DE ITAIPU. Applied Tourism, 4(1), 18- 40.
} 


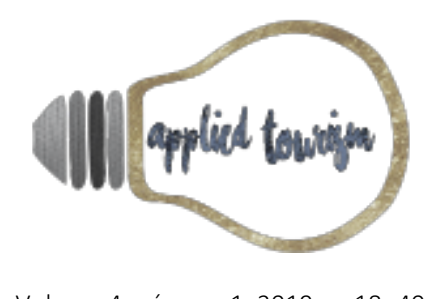

REFLEXOS PARA O MARKETING DE ATRATIVO TURÍSTICO

No que tange ao marketing para o turismo, Coelho (2015) recomenda o uso da inovação e do marketing norteado por pesquisas e tecnologia com o propósito de encantar visitantes e enriquecer suas experiências. Nesse sentido, foram propostos três indicadores a partir da revisão de trabalhos quanto a atração de turistas, mensuração da atratividade de um destino e mensuração da eficácia do marketing. O "indicador reputação" da empresa foi desenvolvido com base em Chun (2005) e Gosling e Coelho (2015).

Chun (2005) compreende que a reputação da empresa diz respeito de como os grupos de interesse percebem a empresa, afirmando ainda que esse reconhecimento pode afetar o nível de satisfação dos clientes, a retenção de empregados, a atração de investidores e o desempenho global da empresa.

Gosling e Coelho (2015) afirmam que a reputação está relacionada às expectativas do cliente a respeito do comportamento da organização, sendo influenciada por atributos como confiabilidade, credibilidade, qualidade e responsabilidade, ressaltando ainda que, no âmbito do turismo, a imagem do destino é parte integrante da formação desse prestígio a partir da experiência e percepção do consumidor.

Em sua revisão quanto ao conceito de reputação, Chun (2005) identificou três escolas de pensamento: a escola da avaliação, que associa a reputação corporativa a partir da performance e desempenho financeiro da empresa, considerada um ativo intangível capaz de gerar vantagem competitiva e cujo o público alvo são acionistas, investidores e CEOs. A escola da impressão, onde a reputação corporativa tem ênfase na associação emocional do stakeholder com a empresa, suas percepções e identificação com a imagem, identidade e personalidade da empresa, tendo como as principais partes interessadas os funcionários ou clientes, abordada pelo marketing para o gerenciamento de imagem e identidade corporativa; e a escola relacional, que enfatiza que a reputação é um alinhamento de três elementos: "como os outros nos veem" (os clientes formando a imagem), "o que realmente somos" (a real identidade da empresa) e "o que nós dizemos que somos" (a identidade desejada) (Chun, 2005, p. 95), considerando que diferentes partes interessadas têm diferentes percepções.

Isso posto, o instrumento para mensuração da reputação da empresa foi proposto a fim de considerar a percepção dos usuários dos óculos de realidade virtual a partir das dimensões de apelo emocional, produtos e serviços e visão da empresa, com objetivo de verificar suas percepções antes e depois da experiência com a realidade virtual.

Para construção do "indicador risco", utilizou-se a proposta dos autores Kotler e Keller (2006) que consideram que a decisão de compra do consumidor pode sofrer interferência do risco percebido, cujo grau varia de acordo Monica, C. L. D. \& NETO, E. H. (2019). A EFICÁCIA DO USO DA REALIDADE VIRTUAL PARA O MARKETING DO ATRATIVO TURÍSTICO USINA DE ITAIPU. Applied Tourism, 4(1), 18- 40. 


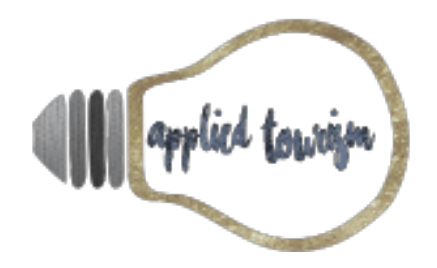

Volume 4, número 1, 2019, p. 18- 40

com o valor do produto/serviço, o nível de incerteza quanto às suas especificidades e nível e autoconfiança do consumidor. Por sua vez, o possível cliente procura reduzir o risco buscando informações adicionais e indicações de sua rede de contatos, dando preferência a marcas já reconhecidas e garantias oferecidas pela empresa.

Kotler e Keller (2006) propõem que o risco percebido pelo consumidor pode ser concebido em 6 dimensões: o risco funcional, de o produto não atender às suas expectativas; risco físico, quando o produto gera uma ameaça à integridade física ou saúde do consumidor ou de terceiros; risco financeiro, quando o produto não vale o preço pago; risco social, quando o uso do produto pode resultar em um constrangimento social; risco psicológico, o uso do produto pode afetar o bem-estar mental do usuário; risco de tempo, a ineficiência do produto resulta em um custo de oportunidade para encontrar um substituto satisfatório. Neste estudo, apenas a dimensão do risco psicológico não será avaliada, pois o produto que será avaliado (o passeio turístico) não oferece riscos ao bemestar mental do usuário.

O "indicador engajamento" foi construído a partir das leituras de Kotler e Keller (2006), devido a reconhecidos estudos na área do marketing, e Pratt, McCabe, Jimenez e Blake (2010) que estudaram campanhas de marketing de destinos turísticos. Kotler e Keller (2006) afirmam que os indicadores de intenção de compra devem ser utilizados pelas empresas a fim de estimar a sua demanda e planejar suas atividades. Enquanto Pratt et al. (2010) realizaram uma pesquisa avaliando o impacto de 18 campanhas de marketing de destinos turísticos, com a verificação da atração de visitantes e o retorno do investimento, chegando a conclusão, que o engajamento é compreendido na motivação do consumidor em visitar a atração turística, a sua intenção de permanecer por mais dias para conhecer a atração, assim como sua intenção de recomendação da atração para outras pessoas.

Figura 1: Indicadores da eficácia do uso da realidade virtual como ferramenta de marketing.

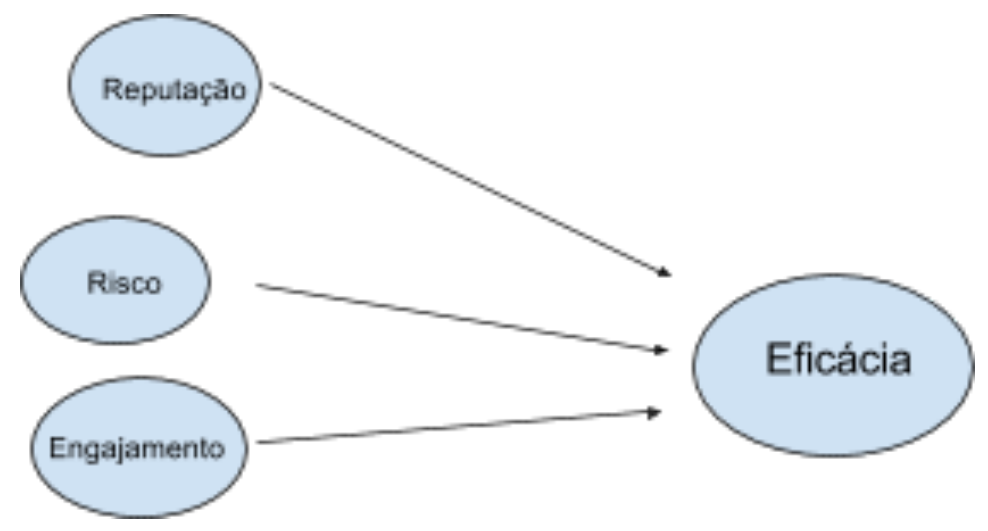

Fonte: Elaboração dos autores. 


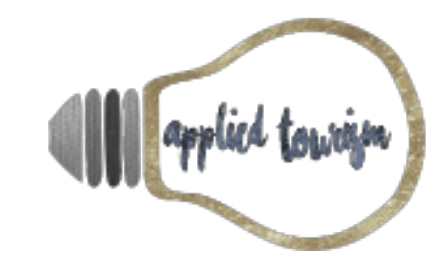

Volume 4, número 1, 2019, p. 18- 40

A escolha dos indicadores ocorreu a partir das leituras de Kotler et al. (2017) a respeito do processo de compra do consumidor na era do marketing digital, passando pelos 5 A's: Assimilação, Atração, Arguição, Ação e Apologia. No A1, de assimilação, o consumidor conhece a marca, mas ainda não tem uma opinião formada sobre ela; no A2, da atração, o consumidor reconhece e gosta da marca, se sentindo atraído por ela. Nesses dois aspectos, o indicador utilizado será o de reputação, com metodologia proposta por Chun (2005). O A3, de arguição, é quando o consumidor busca mais informações sobre o produto/serviço a fim de avaliar o benefício da compra.

Neste quesito, o indicador de risco, citado por Kotler e Keller (2006), será elaborado para mensurar quanto o consumidor se sente seguro em relação ao consumo após o uso da ferramenta de realidade virtual. O A4, de ação, trata-se do estágio em que o consumidor se decide pela compra. No estágio A5, da apologia, o consumidor aprova o produto/serviço e se torna fiel à marca recomendando o seu uso a outros; tais fases serão avaliadas pelo indicador de engajamento, com método desenvolvido a partir das leituras de Pratt et al. (2010), Kotler e Keller (2006) e Kotler et al. (2017), que propõem que os consumidores são cada vez mais dependentes da opinião de outros para tomar suas decisões, da mesma forma que compartilham cada vez mais as suas próprias experiências, formando coletivamente uma imagem da empresa, que pode diferir daquela imagem que a empresa gostaria de comunicar. No segmento do turismo o TripAdvisor e Booking são alguns dos exemplos.

Kotler et al. (2017) destaca que os consumidores não necessariamente seguem uma sequência linear no processo de compra, dependendo do tipo de produto é possível "pular" níveis, ocorrendo uma sequência formato espiral. No caso do consumo de turismo, a fase da arguição é mais extensa, envolvendo muita pesquisa antes da ação de compra. Também podem haver consumidores que advogam pela marca, mesmo sem nunca tê-la consumido, passando diretamente para a fase da apologia, podendo depois retornar à fase da ação, o que é uma característica comum a consumidores de destinos turísticos, que podem ainda não conhecer o destino, mas fazem apologia ao local por ser um desejo de consumo.

Portanto, a proposta desta pesquisa é mensurar os resultados da experiência dos consumidores com a RV, constatando a sua eficácia como ferramenta de marketing para o atrativo turístico Itaipu, a partir dos três indicadores apresentados, ampliando dessa forma, os conhecimentos acerca do impacto da RV em ações de marketing. 


\section{METODOLOGIA}

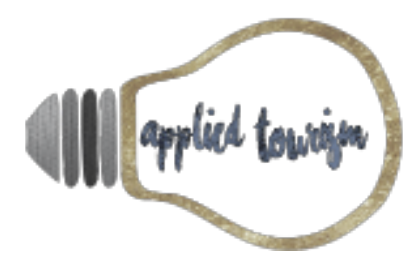

Volume 4, número 1, 2019, p. 18- 40

Trata-se de uma pesquisa descritiva (Gil, 2008), considerada aplicada, devido sua finalidade prática (Ander-Egg, 1978; Rummel, 1972 como citado em Marconi \& Lakatos, 2015), do tipo Survey, caracterizando-se por ser um levantamento de opinião pública pelo método de amostragem, tendo neste estudo a função prática de avaliar a influência da realidade virtual na perspectiva dos indicadores de reputação, risco e engajamento. O instrumento de pesquisa foi questionário estruturado (Baquero, 2009; Marconi \& Lakatos, 2015), com afirmações de avaliação dos indicadores de reputação, risco e engajamento, classificadas em escala do tipo Likert (Likert, 1932; Vieira \& Dalmoro, 2008) de 1 a 7 , sendo 1 não concorda e 7 concorda plenamente. A caracterização da amostra (Tabela 1), utilizou a base de segmentação de demanda empregada pelo Ministério do Turismo Brasileiro [MTB] (2010), que considera o modelo proposto por Kotler e Keller (2006).

Tabela 1: Variáveis e indicadores

Objetivo
Verificar a eficácia do uso da
realidade virtual em relação
ao Indicador de reputação
da empresa

Referência
Chun (2005); Gosling e
Coelho (2015)

Verificar a eficácia do uso da realidade virtual em relação a percepção do consumidor quanto ao risco, a partir do Indicador de risco da empresa

Verificar a eficácia do uso da realidade virtual em relação ao Indicador de engajamento do consumidor

Kotler e Keller (2006); Pratt et al. (2010)

\begin{tabular}{|c|c|}
\hline Dimensões & Questões \\
\hline Apelo emocional & $\begin{array}{l}\text { 1. Tenho uma boa impressão sobre essa empresa } \\
\text { 2. Eu admiro e respeito essa empresa } \\
\text { 3. Eu confio e acredito na competência dessa empresa }\end{array}$ \\
\hline Produtos e serviços & $\begin{array}{l}\text { 4. Essa empresa desenvolve produtos e serviços inovadores; } \\
\text { 5. Essa empresa oferece produtos e serviços de alta } \\
\text { qualidade. }\end{array}$ \\
\hline Visão e aprendizado & $\begin{array}{l}\text { 6. Essa é uma empresa líder no mercado. } \\
\text { 7. Tem uma visão clara para o futuro. } \\
\text { 8. Essa empresa reconhece e aproveita as oportunidades de } \\
\text { mercado. }\end{array}$ \\
\hline $\begin{array}{l}\text { Risco funcional } \\
\text { Risco físico } \\
\text { Risco financeiro }\end{array}$ & $\begin{array}{l}\text { 1. Esse passeio é muito empolgante. } \\
\text { 2.Esse passeio é seguro. } \\
\text { 3. Quanto pagaria para fazer este passeio? (valor em reais) }\end{array}$ \\
\hline Risco social & $\begin{array}{l}\text { 4. É um prestígio para mim fazer este passeio. } \\
\text { 5. Meus amigos vão me admirar por ver que fiz este passeio. }\end{array}$ \\
\hline Risco de tempo & $\begin{array}{l}\text { 6. Só faria este passeio se não tivesse outra coisa para fazer. } \\
\text { 7. Dedicaria um dia do meu lazer para fazer este passeio. }\end{array}$ \\
\hline Intenção de visitação & $\begin{array}{l}\text { 1. Pretendo fazer esse passeio nos próximos dias. } \\
\text { 2. Pretendo fazer este passeio nos próximos } 6 \text { meses. }\end{array}$ \\
\hline $\begin{array}{l}\text { Intenção de } \\
\text { permanência }\end{array}$ & $\begin{array}{l}\text { 3. Gostaria de ficar mais um dia em Foz do Iguaçu para } \\
\text { conhecer esse lugar. }\end{array}$ \\
\hline Recomendação & $\begin{array}{l}\text { 4. Indicaria esse passeio para outras pessoas. } \\
\text { 5. Acredito que outras pessoas deveriam conhecer esse } \\
\text { passeio. }\end{array}$ \\
\hline
\end{tabular}

Fonte: Elaboração dos autores (2017). 


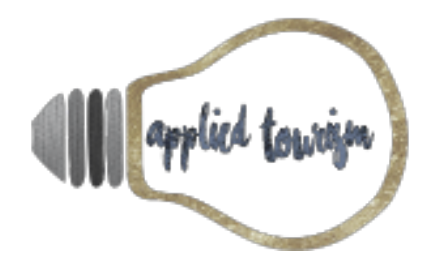

Volume 4, número 1, 2019, p. 18- 40

pesquisa foi devido à disponibilidade do calendário de eventos da Itaipu e ao perfil do seu público alvo, ou seja, de pessoas interessadas em tecnologia e inovação, dessa forma, entende-se que se essas pessoas forem impactadas pelo marketing do atrativo em RV, pessoas com menos afinidades com tecnologias ficarão ainda mais impressionadas e engajadas no consumo ao utilizarem a RV.

Os usuários totalizaram 119 pessoas, sendo que duas pessoas não foram entrevistadas por serem funcionários da Itaipu e uma pessoa desistiu de utilizar os óculos na metade da interação, tendo como população final dessa pesquisa 116 usuários. Ao todo, foram 72 entrevistados, caracterizando uma amostra não-probabilística intencional, com 90\% de confiabilidade e 6\% de margem de erro (Baqueiro, 2009; Agresti \& Finlay, 2012).

A entrevista foi estruturada em seis fases: a apresentação da pesquisa, a avaliação dos indicadores, o uso dos óculos de realidade virtual, a reavaliação dos indicadores após o uso dos óculos e aplicação das questões de caracterização da amostra. Para tanto, foi realizado um pré-teste (Roesch, 2009) no estande da Itaipu no $8^{\circ}$ Seminário Nacional de Operadores de Sistemas e de Instalações Elétricas, nos dias 04 e 05 de outubro de 2017, com a realização de 25 entrevistas, onde se percebeu a necessidade de adaptação das questões a fim de dar maior clareza à redação e eliminar questões redundantes. Os resultados foram tabulados em planilha e para cada indicador foi calculado o valor de média, desvio padrão e o percentual de variação após o uso dos óculos de realidade virtual (Agresti \& Finlay, 2012).

\section{APRESENTAÇÃO, ANÁLISE E EXPLORAÇÃO DOS RESULTADOS}

O Latinoware é um evento que ocorre anualmente no PTI, atraindo principalmente estudantes e profissionais da área de informática e tecnologia de toda a América Latina. No estande da Itaipu, os visitantes podiam experimentar os óculos de RV onde era exibido um vídeo em $360^{\circ} \mathrm{com}$ a simulação de um passeio guiado pela usina e áreas de produção de energia, similar ao passeio real comercializado pela empresa, o passeio "Circuito Especial" (Figura 2). 


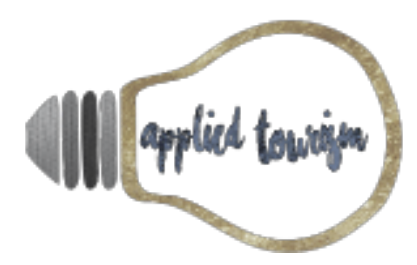

Volume 4, número 1, 2019, p. 18- 40

Figura 2: Usuário da realidade virtual no estande da Itaipu na $14^{\circ}$ Latinoware, óculos de RV e imagens do passeio "Circuito Especial" na Usina de Itaipu.

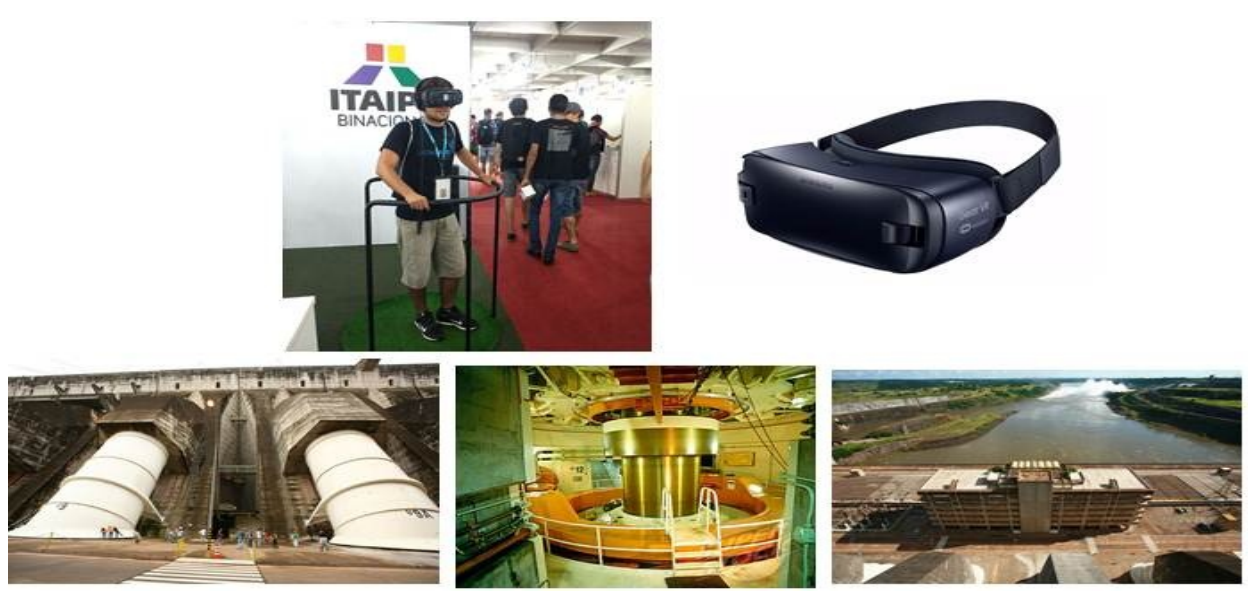

Créditos: dos autores e Google Imagens (2017).

A utilização dos óculos de RV era agendada por horários devido à alta procura e devido ao tempo do vídeo ser de aproximadamente 5 minutos, inviabilizando o uso dos óculos de realidade virtual por todos os interessados.

Tabela 3: Caracterização da amostra

\begin{tabular}{|c|c|c|}
\hline Variável analisada & \multicolumn{2}{|c|}{ Principal índice de respostas } \\
\hline Local de residência & \multicolumn{2}{|c|}{ 58\% (42) residem a mais de $30 \mathrm{~km}$ de distância de Foz do Iguaçu } \\
\hline Nacionalidade & \multicolumn{2}{|c|}{$71 \%$ (51) Brasileiros } \\
\hline Faixa etária & $52 \%$ (37) de 19 a 29 anos & 36\% (26) Até 18 anos \\
\hline Gênero & \multicolumn{2}{|l|}{$65 \%$ (47) Homens } \\
\hline Estado civil & \multicolumn{2}{|l|}{ 92\% (66) Solteiros } \\
\hline Filhos & \multicolumn{2}{|c|}{ 95\% (68) Sem filhos } \\
\hline Composição familiar & \multicolumn{2}{|c|}{$70 \%$ (50) Mora com os pais ou outros parentes } \\
\hline Escolaridade & $46 \%$ (33) Ensino superior incompleto & 31\% (22) Ensino médio incompleto \\
\hline Ocupação profissional & \multicolumn{2}{|l|}{$75 \%$ (54) Estudante apenas } \\
\hline Viagens a negócio/ ano & \multicolumn{2}{|l|}{$78 \%$ (56) não viajam a negócios } \\
\hline Viagens de Férias/ ano & $40 \%$ (29) viajam uma vez por ano & $30 \%$ (22) viajam 2 vezes por ano \\
\hline Planejamento das férias & $34 \%$ (22) mais que três meses & $28 \%$ (18) de um a três meses \\
\hline Viagens em feriados/ano & $44 \%$ (32) não viajam em feriados & $29 \%$ (21) viajam até vezes por ano \\
\hline Planejamento dos feriados & $40 \%$ (16) até um mês & $35 \%$ (14) até uma semana \\
\hline $\begin{array}{l}\text { Viagens para comemorar datas } \\
\text { especiais/ ano }\end{array}$ & \multicolumn{2}{|c|}{$70 \%$ (50) não viajam para comemorar datas especiais } \\
\hline $\begin{array}{l}\text { Principal local que busca informação } \\
\text { sobre a viagem }\end{array}$ & \multicolumn{2}{|c|}{$\begin{array}{l}\text { 80\% (57) vezes foi assinalado "sites de busca", "site de opinião", "facebook" e "site da prefeitura" } \\
26 \% \text { (18) vezes foi assinalado "recomendação de amigos/família" }\end{array}$} \\
\hline O que busca nas viagens a lazer & \multicolumn{2}{|c|}{ 40\% (28) vezes foi assinalado "história/ cultura", "conhecer o lugar", "turismo" } \\
\hline
\end{tabular}
Fonte: Elaboração dos autores (2017).

Devido ao perfil do evento Latinoware, foi predominante a presença de estudantes com até 29 anos de idade. De acordo com a pesquisa do Comitê Gestor da Internet no Brasil [CGI] (2016), cerca de 80\% dos sujeitos nesta faixa etária são usuários habituais de equipamentos da tecnologia da informação e comunicação (computadores, tablets, smartphones), estando expostos às ações de marketing digital. Também são enquadrados como população economicamente ativa, (Instituto Brasileiro de Geografia e Estatística [IBGE], 2017), contudo, o Monica, C. L. D. \& NETO, E. H. (2019). A EFICÁCIA DO USO DA REALIDADE VIRTUAL PARA O MARKETING DO ATRATIVO TURÍSTICO USINA DE 


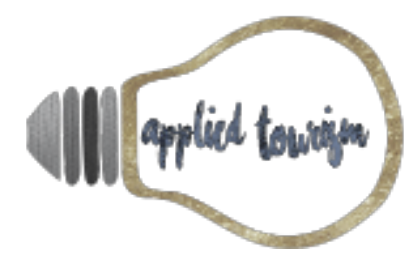

Volume 4, número 1, 2019, p. 18- 40

resultado da pesquisa mostra que 75\% não possuem ocupação profissional e 70\% ainda moram com os pais, exercendo influência nas decisões de consumo familiares, como no caso de viagens, segundo revelado pela pesquisa da Viacom International Media Networks (2011 como citado em Martins, 2015), 74\% dos pais requisitam a opinião dos filhos antes de efetuar uma compra.

Dentre os 29\% paraguaios, predominou a faixa etária de até 18 anos de idade, com 62\% de incidência. Este público demonstrou dificuldade de compreensão das variáveis de reputação da empresa, provavelmente por envolver na avaliação conceitos mercadológicos, os quais não tinham conhecimento suficiente.

A maior parte dos entrevistados, originários de fora de Foz do Iguaçu, visitou a cidade com o principal objetivo de participar do evento e não necessariamente para consumir o Destino Iguaçu, em que um dos atrativos é a Itaipu. Contudo, de acordo com Pearce (2003 como citado em Allis, 2014) poucos locais de um destino turístico são destinados especificamente ao turistas, tendo como exceção o setor de acomodações. Dessa forma, os atrativos turísticos são locais que podem ser consumidos tanto por viajantes quanto pelos residentes do próprio município, onde o comportamento dos moradores inclusive se assemelha ao dos turistas. Este fato é validado pela pesquisa na constatação que 51\% dos que já visitaram a Itaipu são residentes de Foz do Iguaçu ou de cidades com até $30 \mathrm{~km}$ de distância e destes todos estão dispostos a visitar o atrativo novamente, o que mostra que o consumo deste atrativo turístico tem forte participação dos moradores da região, consumo este que também é estimulado pela empresa, que oferece descontos e gratuidade em passeios para este público.

Kotler e Keller (2007) afirmam que a segmentação de clientes a partir de valores comportamentais é a forma mais eficaz para definir segmentos de mercado. Em relação aos hábitos de consumo de viagens, as principais razões de viagens dos entrevistados são desfrutar as férias e feriados (89\% e 56\% dos respondentes respectivamente), sendo a internet o local mais utilizado para obter informações sobre a viagem, o que representa as interações do consumidor com as marcas no modo online. As buscas online se sobrepõe inclusive a recomendação de amigos e familiares (26\%). A opção de materiais impressos, como livros e encartes turísticos, teve apenas um respondente, resultado este que evidencia o impacto da cibercultura no processo de compra do consumidor, que recebe expressiva influência do mundo digital e depois replica as informações para seus grupos sociais mais próximos, como amigos e familiares. Com 10\% de incidência, a opção "agências de viagens" representa a interação do consumidor em modo offline (Kotler et al, 2017).

Quanto às preferências de lazer nas viagens, a opção "História/Cultura" foi a mais assinalada, vindo de encontro com o perfil de atração turística da Itaipu, que apesar de ser considerada um atrativo técnico-científico pelo inventário turístico do Brasil (Lima, 2011), a sua construção fez parte da história do município de Foz do Iguaçu 


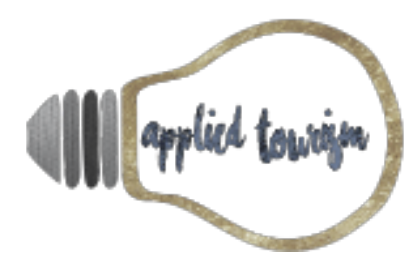

Volume 4, número 1, 2019, p. 18- 40

e do Brasil, sendo considerada a maior usina do mundo em produção de energia, além de oferecer outras estruturas turísticas como Ecomuseu, Refúgio Biológico Bela Vista, Polo Astronômico e Kattamaram. Desse modo, o resultado indica uma predisposição da amostra pesquisada pela visitação deste atrativo. A segunda opção mais assinalada foi "Natureza/Ecoturismo" (25\%), qualidade que também faz parte das opções turísticas oferecidas por Foz do Iguaçu. Cabe ressaltar que nas duas últimas questões o entrevistado poderia indicar mais de uma resposta.

\section{RESULTADOS DOS INDICADORES}

Os sujeitos foram entrevistados antes e depois da utilização dos óculos de realidade virtual, classificando uma série de afirmações em escala Likert de 1 a 7 . No intuito de avaliar os resultados, foram calculados a média e desvio padrão das respostas, assim como o percentual de variação após a visualização do vídeo em realidade virtual (Tabela 4).

Tabela 4: Resultados da percepção da amostra antes e depois do uso do óculos de realidade virtual

\begin{tabular}{|c|c|c|c|c|}
\hline \multirow{3}{*}{ Indicador } & \multirow{3}{*}{ Variáveis } & \multirow{2}{*}{\multicolumn{2}{|c|}{$\begin{array}{c}\text { Resultados } \\
\text { (Média e Desvio Padrão) }\end{array}$}} & \multirow{3}{*}{$\begin{array}{l}\text { Variação de } \\
\text { percepção }\end{array}$} \\
\hline & & & & \\
\hline & & Antes da RV & Depois da RV & \\
\hline \multirow{11}{*}{$\begin{array}{l}\text { Reputação } \\
\text { da } \\
\text { empresa }\end{array}$} & 5. Tenho uma boa impressão sobre a empresa & 6,62 (0,68) & $6,87(0,37)$ & $+0,25$ \\
\hline & 6. Eu admiro e respeito essa empresa & $6,51(0,78)$ & $6,81(0,51)$ & $+0,30$ \\
\hline & 7. Eu confio nessa empresa e acredito na competência dela & 6,41 $(0,98)$ & $6,75(0,66)$ & $+0,34$ \\
\hline & 8. Essa empresa desenvolve produtos e serviços inovadores & $6,27(0,92)$ & $6,55(0,76)$ & $+0,28$ \\
\hline & 9. Essa empresa oferece produtos e serviços de alta qualidade & 6,41 $(0,88)$ & $6,79(0,47)$ & $+0,38$ \\
\hline & 10. Essa é uma empresa líder no mercado & $6,36(0,87)$ & $6,69(0,59)$ & $+0,33$ \\
\hline & 11. Tem uma visão clara para o futuro & $6,33(0,91)$ & $6,62(0,65)$ & $+0,29$ \\
\hline & $\begin{array}{l}\text { 12. Essa empresa reconhece e aproveita as oportunidades de } \\
\text { mercado }\end{array}$ & $6,26(0,99)$ & $6,61(0,72)$ & $+0,35$ \\
\hline & MÉDIA GERAL DO INDICADOR & $6,39(0,87)$ & $6,71(0,59)$ & $+0,32$ \\
\hline & 13. Esse passeio é muito empolgante & $6,43(0,80)$ & $6,91(0,27)$ & $+0,48$ \\
\hline & 14. Esse passeio é seguro & $6,29(1,05)$ & $6,75(0,96)$ & $+0,46$ \\
\hline
\end{tabular}


Volume 4, número 1, 2019, p. 18- 40

\begin{tabular}{|c|c|c|c|c|}
\hline \multirow{4}{*}{ Risco percebido } & $\begin{array}{l}\text { 15. Quanto pagaria para fazer esse passeio } \\
\text { (O valor real do passeio na ocasião da pesquisa era de } \mathrm{R} \$ 78,00)\end{array}$ & $\begin{array}{l}36 \%(26) \\
\text { pagariam de } \\
10 \text { a } 30 \text { reais }\end{array}$ & $\begin{array}{l}21 \%(15) \\
\text { pagariam de } 15 \\
\text { a } 30 \text { reais }\end{array}$ & $\begin{array}{l}39 \% \text { (28) não } \\
\text { mudaram a } \\
\text { percepção }\end{array}$ \\
\hline & & $\begin{array}{l}36 \%(26) \\
\text { pagariam de } \\
40 \text { a } 70 \text { reais }\end{array}$ & $\begin{array}{l}50 \%(36) \\
\text { pagariam de } 40 \\
\text { a } 70 \text { reais }\end{array}$ & $\begin{array}{l}43 \%(31) \\
\text { aumentaram de } \\
10 \text { a } 50 \text { reais }\end{array}$ \\
\hline & & $\begin{array}{l}17 \%(12) \\
\text { pagariam mais } \\
\text { que } 70 \text { reais }\end{array}$ & $\begin{array}{l}28 \%(20) \\
\text { pagariam mais } \\
\text { que } 70 \text { reais }\end{array}$ & \multirow[t]{2}{*}{$\begin{array}{l}11 \%(08) \\
\text { aumentaram } \\
\text { mais que } 100 \\
\text { reais }\end{array}$} \\
\hline & & $\begin{array}{l}10 \%(07) \text { não } \\
\text { sabe }\end{array}$ & $\begin{array}{l}\text { 01\% (01) não } \\
\text { sabe }\end{array}$ & \\
\hline & 16. É um prestígio pra mim fazer esse passeio & $6,55(0,80)$ & $6,80(0,59)$ & $+0,25$ \\
\hline & 17. Meus amigos vão me admirar por ver que fiz este passeio & $5,22(1,77)$ & $5,91(1,47)$ & $+0,69$ \\
\hline & 18. Só faria esse passeio se não tivesse outra coisa para fazer & $1,98(1,71)$ & $1,86(1,73)$ & $-0,12$ \\
\hline & 19. Dedicaria um dia do meu lazer para fazer esse passeio & $6,44(1,03)$ & $6,65(0,92)$ & $+0,21$ \\
\hline \multirow{7}{*}{$\begin{array}{l}\text { Engajamento do } \\
\text { consumidor }\end{array}$} & $\begin{array}{l}\text { MÉDIA GERAL DO INDICADOR (desconsiderando a questão } 15 \text { e } \\
\text { 18) }\end{array}$ & $6,18(1,09)$ & $6,60(0,84)$ & $+0,42$ \\
\hline & 20. Pretendo fazer esse passeio nos próximos dias & $5,20(2,09)$ & $5,68(1,86)$ & $+0,48$ \\
\hline & 21. Pretendo fazer esse passeio nos próximos 6 meses & $5,29(2,14)$ & $5,84(2,00)$ & $+0,55$ \\
\hline & $\begin{array}{l}\text { 22. Gostaria de ficar mais um dia em Foz para conhecer esse } \\
\text { lugar }\end{array}$ & $6,44(1,12)$ & $6,71(0,96)$ & $+0,27$ \\
\hline & 23. Indicaria esse passeio para outras pessoas & $6,80(0,61)$ & $6,90(0,38)$ & $+0,10$ \\
\hline & 24. Acredito que outras pessoas deveriam conhecer esse passeio & $6,81(0,58)$ & $6,95(0,26)$ & $+0,14$ \\
\hline & MÉDIA GERAL DO INDICADOR & $6,11(1,31)$ & $6,41(1,09)$ & $+0,30$ \\
\hline
\end{tabular}

Fonte: Elaboração dos autores (2017).

Os resultados mostram que houve aumento médio de $+0,35$ dos indicadores, contudo, as variações de percepção antes e depois do uso dos óculos de RV não ultrapassaram a casa de decimais, pois a avaliação anterior da utilização dos óculos já foram bastante altas, demonstrando que a Usina de Itaipu é uma empresa reconhecida e admirada pelo público pesquisado especialmente pelo público que visitou (notadamente composto por pessoas que residem nas proximidades), e o óculos de realidade virtual vem consolidar essa admiração e instigar o engajamento do consumidor. Da mesma forma, constatou-se o baixo valor de desvio padrão, indicando a concentração das respostas nos valores mais altos da escala. 


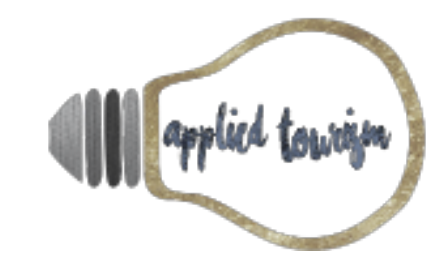

Volume 4, número 1, 2019, p. 18- 40

\section{Verificação da eficácia do uso da realidade virtual em relação ao Indicador de Reputação da Empresa}

O indicador de reputação da empresa obteve a segunda maior variação de respostas $+0,32$ e o menor valor de desvio padrão, consolidando a boa percepção do público pesquisado em relação à reputação da empresa. A mudança de percepção mais expressiva foi em relação à alta qualidade dos produtos e serviços oferecidos pela Usina de Itaipu, com aumento de +0,38 na percepção do usuário logo após o uso dos óculos de realidade virtual, provavelmente devido à ênfase do vídeo no passeio Circuito Especial, visitando as áreas de produção de energia da usina, ou seja, apresentando dois produtos da Itaipu: a energia e o passeio turístico. Porém, 8\% dos entrevistados diminuíram a pontuação atribuída a variável número 8 , referente à inovação dos produtos e serviços oferecidos pela empresa, provavelmente devido à ênfase do vídeo nas áreas de produção de energia, não sendo este um serviço inovador aos olhos dos sujeitos desta pesquisa e considerando que o evento Latinoware abordava justamente de inovações tecnológicas.

Pode-se considerar de acordo com Chun (2005), que a empresa comunica de forma eficaz a sua identidade, permitindo ao público externo a formação de uma boa imagem da organização, assim como, o nível de satisfação com a empresa é elevado. Neste quesito, os óculos de realidade virtual reforça a imagem positiva da empresa, gerando um impacto favorável na percepção dos usuários óculos de realidade virtual. O resultado do indicador de reputação também mostra que os entrevistados assimilam com facilidade a marca Itaipu e se sentem atraídos por ela, confirmando a eficácia das ações de marketing e a aprovação das atitudes da empresa pelo público (Kotler et al., 2017). Considerando Gosling e Coelho (2015), o fato do indicador de reputação ter apresentado variação positiva confirma que as expectativas dos clientes foram atendidas ou até superadas após a visualização em RV.

\section{Verificação da eficácia do uso da realidade virtual em relação ao Indicador de Risco Percebido}

Quanto ao indicador de risco percebido, foram 6 afirmações para serem classificadas em escala de 1 a 7, sendo que na afirmação 18 que visava aferir a dimensão de risco temporal, possui sentido invertido com o intuito de validar a atenção do usuário, dessa forma, a pontuação 1, que significa a discordância, é a mais satisfatória para a empresa, por esse motivo foi desconsiderada para o cálculo da média geral. Justamente esta afirmação foi a que obteve a menor variação $(-0,12)$, indicando o desejo e preferência dos entrevistados em fazer o passeio Circuito Especial mesmo antes de experimentar a realidade virtual, o que revela o baixo nível de incerteza quanto ao 


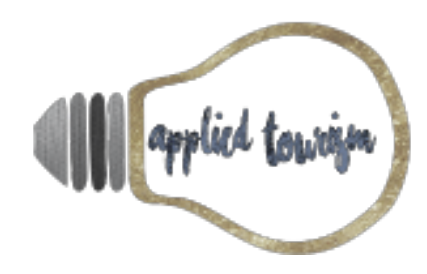

Volume 4, número 1, 2019, p. 18- 40

passeio. Ademais, é natural que os consumidores sintam-se seguros com marcas reconhecidas no mercado, como a Itaipu (Kotler \& Keller, 2006).

Quanto ao risco financeiro na afirmação de preço percebido, o usuário atribuiu um valor que pagaria para fazer o passeio Circuito Especial (os estrangeiros atribuíam valor na moeda do seu país, que foi convertido para reais considerando a taxa de câmbio da data da pesquisa); neste item, $60 \%$ dos entrevistados aumentaram o valor que pagariam para fazer o passeio após a utilização dos óculos de realidade virtual, contudo, $71 \%$ dos valores citados estão abaixo do valor real do produto que na ocasião desta pesquisa era de $\mathrm{R} \$ 78,00$, portanto, ao saber o valor real deste, há a possibilidade de o consumidor reavaliar a sua intenção de compra devido à dimensão financeira.

Dentre todas as afirmações, a que apresentou maior variação foi a número 19, representando a dimensão de risco social em relação à admiração que teria de amigos ao fazer o passeio Circuito Especial. Nesse quesito, o aumento da pontuação foi de $+0,69$ após o uso da RV, indicando o aumento da percepção de admiração social (Kotler \& Keller, 2007). Da mesma forma, a dimensão funcional, que aferia sobre a empolgação do sujeito em relação ao passeio, obteve variação positiva em $+0,48$ e menor desvio padrão após a experiência em realidade virtual, indicando que, por meio da ferramenta de RV, houve aumento da percepção do serviço oferecido pelo atrativo, o qual obteve a aprovação dos usuários com o resultado mais próximo da avaliação máxima.

Avaliando em conjunto com as demais afirmações de risco, pode-se afirmar que mesmo antes do uso da RV o risco percebido foi baixo, revelando alto grau de confiança dos usuários na empresa e reconhecimento da qualidade do produto turístico. Para os entrevistados, fazer este passeio impacta positivamente na sua autoestima e imagem social, havendo um aumento da valorização do passeio após o uso da realidade virtual e diminuição do risco físico e de tempo. Em relação ao processo de compra do consumidor na era digital, o no estágio da arguição, pode-se aferir que a experiência e informações contidas no vídeo em realidade virtual ampliaram a percepção do usuário quanto ao benefício da compra e sua segurança em relação ao consumo, resultando a contribuição da ferramenta de realidade virtual para a eficácia do marketing (Kotler et al., 2017).

\section{Verificação da eficácia do uso da realidade virtual em relação ao Indicador de Engajamento}

O indicador de engajamento do consumidor foi o que obteve as menores médias e com a menor oscilação de respostas $(+0,30)$, contudo, também apresentou o maior valor de desvio padrão dentre os indicadores. Ainda assim, após a experiência com a realidade virtual a média das afirmações foram superiores e houve a diminuição do desvio padrão. Cabe destacar os resultados da caracterização da amostra apontaram a predisposição do público pesquisado pela visitação do atrativo turístico Itaipu devido ao seu valor histórico e cultural para o Brasil 


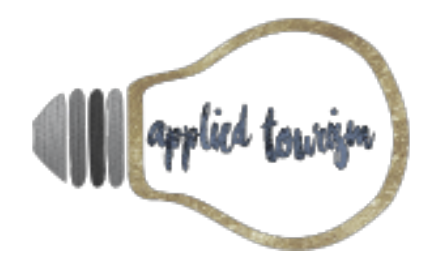

Volume 4, número 1, 2019, p. 18- 40

e para o município de Foz do Iguaçu, convalidando as altas médias deste indicador mesmo antes da experiência com a realidade virtual.

A alta variação do desvio padrão foi influenciada principalmente pela dimensão "intenção de visitação", cujas médias ficaram abaixo de 6,0 e desvio padrão de 2,11 antes e 1,93 depois da RV. Um possível motivo para essa dimensão ter apresentado o menor resultado dentre os indicadores, é fato de a pesquisa ter ocorrido durante o evento Latinoware, cujo objetivo do público entrevistado era a participação no evento e não a experiência de consumo do destino Foz do Iguaçu, estando impossibilitados de fazer o passeio devido à programação de atividades do evento. Entretanto, os entrevistados manifestaram o desejo de conhecer o atrativo turístico, ao revelarem a intenção de permanecer em Foz do Iguaçu para conhecer este lugar; afirmação que obteve média superior a 6,0. Outra justificativa para o resultado da "intenção de visitação" é devido algumas pessoas já terem feito o passeio Circuito Especial e terem menor intenção em visitá-lo novamente. No caso da afirmação 20, foi atribuída nota inferior a 6 após a RV por 27 pessoas, das quais 37\% já haviam feito o passeio Circuito Especial.

A afirmação 21 teve 19 respondentes, cuja nota foi inferior a 6 após a RV, destes 32\% já haviam feito o passeio. Não obstante, todos que já fizeram o passeio afirmam que o fariam novamente, restando concluir que a média abaixo de 6 para as afirmações "intenção de visitá-lo novamente nos próximos dias" ou nos próximos 6 meses, é devido uma impossibilidade pessoal, não relacionada aos atributos do passeio ou do vídeo em RV.

Quanto à intenção de recomendação para outras pessoas, a média foi alta $(6,8)$ mesmo antes do uso da RV, mantendo variação positiva e diminuição do valor de desvio padrão após o uso da realidade virtual, ou seja, houve maior consenso nas respostas após o uso dos óculos. Em relação à apologia da marca, os resultados mostram que 93\% dos entrevistados estão dispostos a recomendar a visitação para outras pessoas (notas 7) após a RV, e ainda 91\% acreditam ainda que outras pessoas deveriam realmente conhecer este local.

Destaca-se por fim que Kotler et al. (2017) afirmam que os consumidores são cada vez mais dependentes da opinião de seus pares para tomarem decisões, da mesma forma que compartilham cada vez mais as suas próprias experiências. Neste quesito, a Itaipu já possui alta intenção de recomendação do passeio Circuito Especial e a RV reforça uma avaliação que já é alta, influindo de modo positivo na percepção do usuário. Esse resultado também é um reflexo do desempenho positivo do indicador de reputação da empresa, pois Chun (2005) afirma que a percepção desta interfere no nível de satisfação dos clientes, além de aumentar os níveis de confiança perante a marca. 


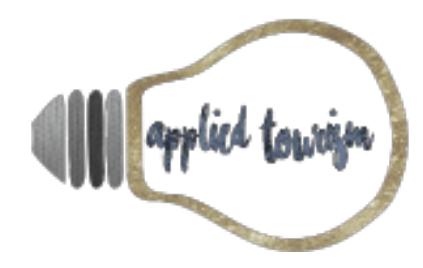

Volume 4, número 1, 2019, p. 18- 40

Assim sendo, a eficácia da RV para o engajamento do consumidor é comprovada na constatação das maiores avaliações após a visualização do conteúdo em realidade virtual, no entanto, no caso do atrativo Itaipu, se observa a motivação dos usuários por visitar o atrativo e recomendar a outras pessoas, mesmo antes do uso da ferramenta, o que confirma a boa reputação da empresa.

\section{APLICABILIDADE DOS RESULTADOS}

A realidade virtual utilizada como ferramenta de marketing tem o intuito de proporcionar uma experiência imersiva do usuário no ambiente da marca e se tornou uma alternativa para criação de experiência única, inovadora e emocionante para prospects da empresa (Poggi, 2016; Steimer \& Conick, 2018). O uso da RV como comunicação de marketing é eficaz, já que a imersão do usuário promove experiências realísticas com a marca, induzindo a atitudes positivas do consumidor, assim como intenções de compra mais elevadas (Kerrebroeck, Brengman \& Willems, 2017).

No estande de uma empresa durante uma feira ou evento, onde existem diversos outros estandes para se visitar, a realidade virtual torna-se um diferencial que atraí prospects para uma visita no espaço da empresa e possibilita que, em um curto espaço de tempo, o prospect tenha uma concepção completa da empresa por meio da experiência imersiva, onde o receptor da comunicação deixa de ser passivo e passa a viver a propaganda como protagonista, a partir de uma sensação corporal total (La Peña, 2015), ou como sugere Milk (2015), sentindo a história de modo profundo. Constata-se com esta pesquisa que a realidade virtual é capaz de aumentar as percepções de reputação da empresa, diminuir o risco associado a uma visita no atrativo turístico que é uma Usina Hidrelétrica e aumentar o engajamento pela visita, pois, mesmo a pesquisa tendo sido realizada dentro da área da Usina, onde os sujeitos já tiveram um contato inicial com o atrativo, ainda assim houve variação favorável dos indicadores após o experimento com a realidade virtual.

As pessoas são guiadas por novidades, nesse sentido, o destaque não é apenas para os óculos de realidade virtual, mas sim para as possibilidades que esta tecnologia tem em gerar uma experiência singular dos prospects com as empresas, concedendo vivacidade à marca (Kerrebroeck et al., 2017) e criando situações de envolvimento profundo com os consumidores. Além do impacto ao próprio usuário da realidade virtual, é possível ainda o planejamento de ações que incentivem o compartilhamento das experiências imersivas em redes sociais como forma a dar maior visibilidade à marca.

No que tange ao segmento de atrativos turísticos, objeto deste estudo, a realidade virtual concede a tangibilidade do serviço para os prospects. Ao considerar o objeto deste estudo, oferece uma amostra imersiva de um passeio 


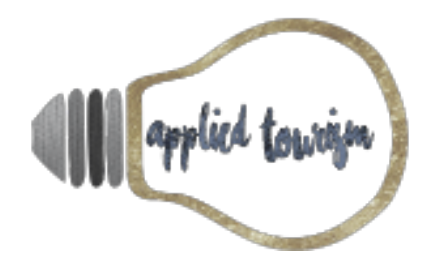

Volume 4, número 1, 2019, p. 18- 40

real, onde o usuário tem a percepção que está pessoalmente no atrativo, dessa forma, ele consegue perceber a grandiosidade e beleza da Usina de Itaipu e cria expectativas para uma futura visita ao atrativo. Ademais, como mostram os resultados da pesquisa, o passeio virtual pela Usina, proporcionou maior reputação da empresa pela percepção dos usuários e, especialmente, aumento da percepção de qualidade dos serviços oferecidos pela empresa.

Se tratando de uma Usina Hidrelétrica, cujo principal finalidade não é ser um atrativo turístico, e sim a produção de energia, o fator "risco percebido" diminuiu com o passeio virtual pela Usina, principalmente em relação à motivação para se conhecer o atrativo, que pode ser percebido pela empolgação em conhecer o passeio, o mérito em visitar o local e a disponibilidade para pagar pela visita, assim como, em relação à sensação de segurança em visitar esta área industrial.

\section{CONSIDERAÇÕES FINAIS}

Este estudo apresentou como a era digital alterou a maneira como o ser humano vive e se relaciona, assim como as relações de consumo ressaltando que, para se manterem no mercado e conquistarem espaço na mente dos consumidores, as marcas devem acompanhar a revolução tecnológica e utilizá-la em seu benefício, criando momentos de envolvimento profundo com seus clientes e prospects. Neste contexto, a tecnologia da RV está cada vez mais acessível e tem grande potencial de popularização. Para os setores de marketing e publicidade das empresas, representa uma ferramenta inovadora e de baixo custo, capaz de gerar o envolvimento profundo e de alto impacto nos consumidores.

Tendo os resultados dessa pesquisa relacionados com o processo de compra do consumidor proposto por Kotler et al. (2017), afirma-se que o estágio da assimilação da marca é superado pelos entrevistados, pois já conheciam a Itaipu, no entanto, a RV reforçou a boa impressão dos entrevistados quanto aos atributos de reputação da empresa.

O estágio da atração do consumidor pela empresa também já ocorria aos entrevistados previamente, constatado nas altas avaliações mesmo antes da experiência com a realidade virtual, o que demonstra a confiança e admiração pela organização, cujos resultados são superiores após a experiência em realidade virtual. O estágio da arguição ocorreu nesta pesquisa com a utilização dos óculos de RV, onde o vídeo apresentou mais informações sobre a empresa e o passeio turístico Circuito Especial, permitindo ao usuário avaliar o benefício da compra.

O estágio da ação, demonstrado pelo indicador de engajamento, aponta que os usuários entrevistados aumentaram sua intenção de fazer o passeio após assistir o vídeo de RV, ainda que não tivessem a possibilidade Monica, C. L. D. \& NETO, E. H. (2019). A EFICÁCIA DO USO DA REALIDADE VIRTUAL PARA O MARKETING DO ATRATIVO TURÍSTICO USINA DE ITAIPU. Applied Tourism, 4(1), 18- 40. 


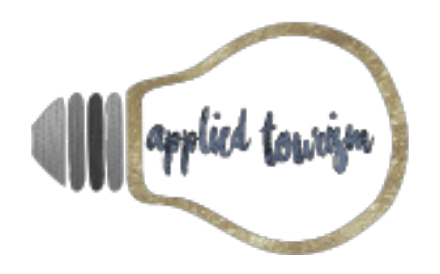

Volume 4, número 1, 2019, p. 18- 40

de fazê-lo naquele momento, devido à programação do evento que participavam. E o estágio da apologia à marca, que obteve a menor variação dentre as afirmações do indicador de engajamento, pois os usuários demonstraram alta intenção de recomendação do passeio antes mesmo da experiência com a tecnologia de realidade virtual e, mesmo aqueles que já haviam feito o passeio, revelam sua intenção de retornar.

Do total de entrevistados, 57 já haviam visitado a Itaipu e 20 tinham feito o passeio Circuito Especial, portanto, o conteúdo do vídeo em RV exibia locais e fatos os quais essas pessoas tinham algum conhecimento e impressões prévias acerca da reputação da empresa, o risco envolvido em fazer o passeio, assim como, intenções de nova visitação e recomendação do passeio. Além disso, todos entrevistados estariam dispostos a fazer este passeio novamente, o que reforça as percepções positivas sobre a empresa e justifica as altas avaliações dos indicadores, mesmo antes do uso dos óculos de RV.

Com as variações positivas de todos os indicadores após o uso da realidade virtual, é possível constatar a sua eficácia ao ser utilizada como ferramenta de marketing para o atrativo turístico Itaipu, tendo como público-alvo jovens de 18 a 29 anos. A ferramenta se mostrou capaz de gerar percepções positivas nos aspectos de reputação da empresa, assim como, diminuir o risco percebido de consumo do produto, além de estimular o desejo de fazer o passeio turístico.

Como limitação da pesquisa destaca-se a quantidade de usuários na faixa etária abaixo de 18 anos, que não tinham conhecimento suficiente para avaliar as variáveis de reputação da empresa, que envolviam conceitos mercadológicos; o fato do evento ocorrer dentro do PTI, podendo ter influenciado a percepção dos usuários antes do uso dos óculos de RV, possível razão para as altas avaliações antes do uso deste recurso. Além da limitação intrínseca do método de entrevista como a incompreensão por parte do respondente e possibilidade de influência do pesquisador (Marconi \& Lakatos, 2015). Em relação à amostra não probabilística pode haver tendenciosidade amostral, onde o resultado pode não ter a representatividade da população (Agresti \& Finlay, 2012).

Como proposta de pesquisas futuras, seria interessante realizar a mesma pesquisa em municípios/países distantes do atrativo turístico, onde os usuários (com distintas faixas etárias e culturas) tivessem pouco conhecimento sobre a empresa ou passeio, dessa forma a RV pudesse ser mais impactante, refletindo em maiores variações dos indicadores antes e após o uso dos óculos. 
REFERÊNCIAS

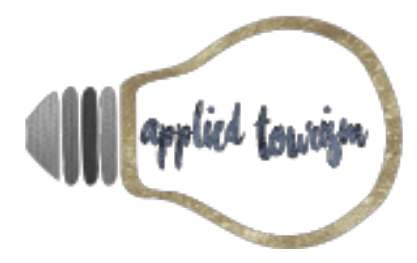

Volume 4, número 1, 2019, p. 18- 40

Agresti, A., \& Finlay, B. (2012). Métodos estatísticos para as ciências sociais (4a ed.) (L. Viali Trad.). Porto Alegre: Editora Penso.

Allis, T. (2014). Viajantes, visitantes, turistas... em busca de conceitos em um mundo urbano. Caderno Virtual de Turismo. Edição especial: Hospitalidade e políticas públicas em turismo, 14(1), 23-38.

Baquero, M. (2009). Pesquisa quantitativa nas ciências sociais. Porto Alegre: Editora UFRGS.

Bogmann, I. M. (2000). Marketing de relacionamento, estratégias de fidelização e suas implicações financeiras. São Paulo: Editora Nobel.

Chun, R. (2005). Corporate reputation: meaning and measurement corporate reputation: meaning and measurement. International Journal of Management Reviews, 7(2), 91109. doi:10.1111/j.1468-2370.2005.00109.x

Coelho, M. F. (2015). O Que atrai o turista? Gestão da competitividade de destinos a partir de atrações e da atratividade turística. Revista Rosa dos Ventos Turismo e Hospitalidade [dossiê - competitividade das destinações turísticas],7(4), p. 489-505. doi: http://dx.doi.org/10.18226/21789061.v7iss4p489

Comitê Gestor da Internet no Brasil. (2017). Pesquisa sobre o uso das tecnologias de informação e comunicação nos domicílios brasileiros: TIC domicílios 2016 (Relatório de Pesquisa), São Paulo, SP, Núcleo de Informação e Coordenação do Ponto BR.

Consultoria Gartner Group. (2016, Outubro). Top strategic predictions for 2017 and beyond: surviving the storm winds of digital disruption. Recuperado em 18 de dezembro, 2017, de https://www.gartner.com/doc/3471568?srcld=1-3478922254

Consultoria Gartner Group. (2017, maio). Transform Business Outcomes With Immersive Technology. Recuperado em 18 de dezembro, 2017, de https://www.gartner.com/smarterwithgartner/transform-business-outcomes-withimmersive-technology/

Gil, A. C. (2008). Como elaborar projetos de pesquisa (4a ed.). São Paulo: Atlas.

Gosling, M., \& Coelho, M. F. (2015). Em Busca da Definição de Reputação de Destinos Turísticos: significados e temas associados a partir da visão de profissionais. Revista Turismo em Análise, 26(2). doi: http://dx.doi.org/10.11606/issn.1984-4867.v26i2p262-281.

Interactive Advertising Bureau. (2016). Is virtual the new reality? (A market snapshot of VR publishing and monetization Report). New York, NY. 


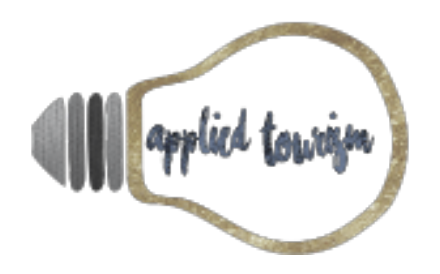

Volume 4, número 1, 2019, p. 18- 40

Instituto Brasileiro de Geografia e Estatística. (2017). Indicadores IBGE: Pesquisa Nacional por Amostra de Domicílios Contínua - Terceiro Trimestre de 2017 (Relatório de pesquisa). Rio de Janeiro, RJ. Recuperado em 02 de dezembro, 2017, de https://ww2.ibge.gov.br/home/estatistica/indicadores/trabalhoerendimento/pnad_co ntinua/default.shtm

Kerrebroeck, H. V.; Brengman, M; Willems, K (2017). When brands come to life: experimental research on the vividness effect of Virtual Reality in transformational marketing communications. Virtual Reality, 21, 177-191. doi: 10.1007/s10055-017-0306-3.

La Peña, N. (2015, maio). The future of News? Virtual Reality [Vídeo file]. TEDWomen 2015 Recuperado de https://www.ted.com/talks/nonny_de_la_pena_the_future_of_news_virtual_reality >

Lima, A. C. G. (2011). Inventário da oferta turística 2011. Brasília, DF, Ministério do Turismo. Recuperado em 05 de dezembro de 2017, de http://www.inventario.turismo.gov.br/invtur/jsp/formularios/

Siscoutto, R. A., \& Kirner, C. (2007). Realidade virtual e aumentada: conceitos, projeto e aplicações. Porto Alegre: Petrópolis (SBC - Sociedade Brasileira de Computação).

Kirner, C., \& Tori, R. (2004). Realidade virtual: conceitos e tendências [Livro do Pré-Simpósio SVR 2004 - VII Symposium on Virtual Reality]. São Paulo: Mania de Livro.

Keller, K., \& Kotler, P. (2006). Administração de marketing (12a ed.) (M. Rosenberg, C. Freire, B. R. Fernandes Trad.). São Paulo: Pearson Prentice Hall.

Kotler, P., Kartajaya, H., \& Setiawan, I. (2017). Marketing 4.0: do tradicional ao digital (I. Korytowski Trad.). Rio de Janeiro: Sextante.

Likert, R. (1932). A Technique for the Measurement of Attitudes (Vol. 22, pp. 05 - 55): Archives of Psychology n.140. New York: Woodworth Editor.

Marconi, M. A. \& Lakatos, E. M. (2015). Técnicas de pesquisa. São Paulo: Atlas.

Martins, I. S. S. (2015, setembro). A Criança como Influenciadora de Compra: Fatores de Estímulo e a Participação da Publicidade neste Comportamento. Anais XXXVIII Congresso Brasileiro de Ciências da Comunicação, Rio de Janeiro, RJ, Brasil.

Milk, C. (2015). How virtual reality can create the ultimate empathy machine [Vídeo file]. TED. Recuperado de https://www.ted.com/talks/chris_milk_how_virtual_reality_can_create_the_ultimate _empathy_machine >

Ministério do Turismo. (2010). Segmentação do turismo e o mercado [caderno]. Brasília, DF, Secretaria Nacional de Políticas de Turismo, Departamento de Estruturação, Articulação e Ordenamento Turístico, Coordenação Geral de Segmentação. 


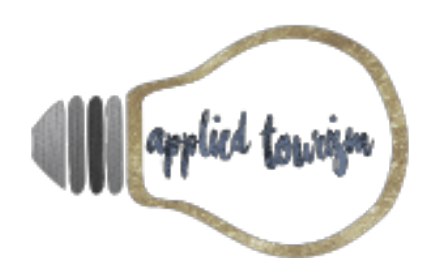

Volume 4, número 1, 2019, p. 18- 40

Neff, J. (2015, julho). Realidade Virtual invade o marketing. Revista Meio \& Mensagem. Recuperado em 12 de setembro, 2017, de http://www.meioemensagem.com.br/home/marketing/2015/07/09/realidade-virtualinvade-o-marketing.html

Okada, S. I., \& Souza, E. M. S. (2011). Estratégias de marketing digital na era da busca. REMark - Revista Brasileira de Marketing, 10(1), 46 - 72. doi: http://dx.doi.org/10.5585/remark.v10i1.2199.

Secretaria Especial de Comunicação Social. (2016). Pesquisa Brasileira De Mídia 2016: hábitos de consumo de mídia pela população brasileira (Relatório de pesquisa). Brasília, DF, Secom, Presidência da República, Brasil.

Poggi, J. (2016). The cmo's guide to virtual reality. Advertising Age, 16 May 2016, p. 0030. Academic OneFile, Recuperado em 30 de agosto, 2018, de <http://link.galegroup.com/apps/doc/A452742313/AONE?u=capes\&sid=AONE\&xid=1 ead57c8>. Acesso em 26/08/2018.

Porciuncula, L., \& Infante, J. (2016). Agendas digitais na América Latina e Caribe: boas práticas para aproveitar as oportunidades da economia digital. In Comitê Gestor da Internet no Brasil. Pesquisa sobre o uso das tecnologias de informação e comunicação nos domicílios brasileiros [livro eletrônico]: TIC domicílios 2015. São Paulo: Comitê Gestor da Internet no Brasil.

Pratt, S., Mccabe, S., Jimenez, I. C., \& Blake, A. (2009). Measuring the effectiveness of destination marketing campaigns: comparative analysis of conversion studies. Journal of Travel Research, 49(2), 179-190. doi: https://doi.org/10.1177/0047287509336471.

Roesch, S. M. A. (2009). Projetos de estágio e de pesquisa em administração: guia para estágios, trabalhos de conclusão, dissertações e estudos de caso (3a ed.). São Paulo: Atlas.

Schwarzelmüller, A. F. (2005, junho). Inclusão digital: uma abordagem alternativa. Anais VI Encontro Nacional de Ciência da Informação: informação, conhecimento e sociedade digital. Salvador, BA, Brasil. Recuperado em 12 de setembro, 2017, de <http://bogliolo.eci.ufmg.br/downloads/SCHWARZELMULLER\%20Inclusao\%20digital\% 20uma\%20abordagem\%20alternativa.pdf> Acesso em 12/09/2017.

Steimer, S.; Conick, H. (2018, agosto). What does the future of customer experience look like? American Marketing Association - AMA. Recuperado em 30 de agosto, 2018, de < https://www.ama.org/publications/MarketingNews/Pages/what-does-futurecustomer-experience-look-like.aspx> Acesso em 26/09/2018. 


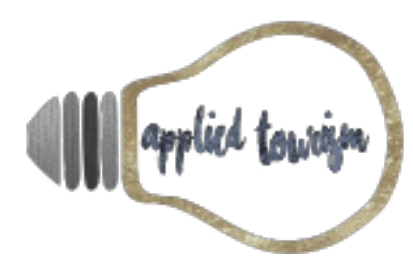

Volume 4, número 1, 2019, p. 18- 40

Vieira, K. M., \& Dalmoro, M. (2008, setembro). Dilemas na construção de escalas tipo likert: o número de itens e a disposição influenciam nos resultados? Anais XXXII Encontro da ANPAD, Rio de Janeiro, RJ, Brasil. 